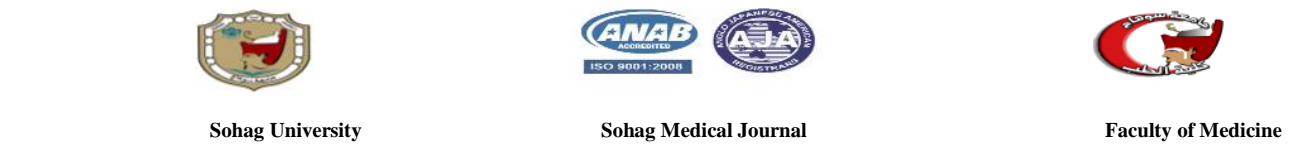

\title{
Recommendations for oncological surgical practice in COVID-19 pandemics: a review of literature Emad Ali Ahmed MD, PhD
}

\author{
Hepatobiliary surgery unit, general surgery department, faculty of \\ medicine, Sohag University, Sohag, Egypt.
}

\begin{abstract}
While the whole world is gaining more and more achievements and progression in several fields, a corona pandemic comes to brake this progress and find us lacking many crucial points. One of these points is to have an emergency protocol for performing different types of surgery in such pandemic states. This led to floundering in surgical decisions for many patients. This review summarizes some recommendations for performing surgeries, especially oncological surgery in the corona pandemic. As a general protection measure, all surgical patients and medical staff must complete preoperative screening whatever symptomatic or not. The medical staff should comply with the regulations of the health facilities to decrease the viral transmission between the medical staff themselves and their patients. Moreover, correct protective apparel (goggles, visor, mask, and protective bodysuit) must be routine. When dealing with a suspected case or a diagnosed patient, tertiary dress code, increasing the operative room ventilation, and installing air purification equipment should be applied. In conclusion, elective surgeries are recommended to be discontinued to avoid patients' and health professionals' morbidity and mortality. Emergency and oncological surgeries to be performed with extreme precautions.
\end{abstract}

Keywords: corona; surgery; oncological; recommndations; guidline.

\section{OVERVIE}

\section{Introduction:}

Coronaviruses is related to the family Coronaviridae. They are categorized into four generations: Alpha-, Beta-, Gamma-, and Delta-coronavirus. Nowadays, seven coronaviruses (HCoVs) have been described in humans, which fall within the Alpha- and Beta-coronavirus genera. The Alpha-coronavirus family includes HCoVNL63 and HCoV229E, while the Beta-coronaviruses contains HCoV-OC43, HCoV-HKU1, SARS-CoV (severe acute respiretory syndrome coronavirus), MERS-CoV (Middle East respiratory syndrome coronavirus), and the new one SARSCoV-2 (severe acute respiratory syndrome coronavirus 2) (1).

The newly described coronavirus disease 2019 (COVID-19) has resulted from the infection with SARS-CoV-2 (2). COVID-19 is responsible for the third pandemic of coronavirus family after SARS (2002) and MERS (2012). Nearly all countries are affected, and the World Health Organization declares that $6,663,304$ patients are currently confirmed, and 392,802 deaths have resulted as of 6 June 2020. 


\section{Diagnosis:}

Cases infected with SARS-CoV-2 can present clinically with different symptoms ranging from mild to severe. In a case series ( 3 ) that included 138 patients with COVID-19, patients' clinical manifestations according to the commonest were included fever $(98.6 \%)$, fatigue (69.6\%), dry cough (59.4\%), anorexia (39.9\%), myalgia (34.8\%), dyspnea (31.2\%), expectoration (26.8\%), diarrhea (10.1\%), nausea (10.1\%), headache (6.5\%), vomiting (3.6\%), abdominal pain $(2.2 \%)$. The diagnostic laboratory tests revealed normal or decreased leukocyte counts, lymphopenia with lymphocyte count, $0.8 \times 10^{9} / \mathrm{L}$ in $70.3 \%$ of infected patients associated with prolonged prothrombin time (13.0 seconds, 58\%), elevated LDH (261 U/L, $39.9 \%$ ). Radiographic pictures of pneumonia in the form of multiple mottling and ground-glass opacity, is present in $100 \%$ of patients with sequelae of or organ failure (shock $30.6 \%$, acute respireatory distress syndrome [ARDS] $61.1 \%$, acute cardiac injury $44.4 \%$ ) and death in severe cases $(\underline{3})$.

\section{Viral transmission:}

The transmission mechanism of SARSCoV-2 is not exactly understood. Droplet transmission from human to a human is the principal route of transmission among a susceptible population (1). Scientific literature has shown that SARS-CoV and MERS-CoV are viable under conditions promoting fecooral transfer. Therefore, another possible way of transmission is the feco-oral route (4).

In a recent experimental study, the aerosol stability of the SARS-CoV-2 showed that SARS-CoV-2 remained alive in the aerosols along the duration of the test ( 3 hours), but with a decrease of the infectious titer. Moreover, the surface stability of the virus represented the most prolonged viability on stainless steel and plastic than on cards and copper. The estimated median half-life of SARS-CoV-2 was approximately 5.6 hours on stainless steel while it was 6.8 hours on plastics. Therefore, the aerosol and fomite spread of SARS-CoV-2 is reasonable, since the virus can remain alive and infectious in air for hours and on surfaces up to days (ㅁ).

\section{SURGERY IN COVID-19 PANDEMIC}

Concerns are primarily focused on the risk of viral transmission during operations. Obviously, there is an evidence that COVID-19 is disseminated through close contact by airway droplets and fomites. However, airborne risks of transmission are possible and being the highest during procedures that generates aerosols such as intubation, extubation, laparoscopy, and endoscopy. These procedures pose significant risks to the anesthesiologists, surgeons, and nursing staff within the operative room (OR) (ㅁ). As a general protection measure, all surgical patients and medical staff must complete preoperative screening whatever symptomatic or not. The medical staff should comply with the regulations of the health facilities to decrease the viral transmission between the medical staff themselves and their patients. Moreover, correct protective apparel (goggles, visor, mask, and protective body-suit) must be routine. When dealing with a suspected case or a diagnosed patient, tertiary dress code, increasing the OR ventilation, and installling air purification equipment should be applied $(\underline{7}, \underline{8})$.

On March 31, 2020, the American college of surgeons launched a new guideline which states that non-emergent 
SOHAG MEDICAL JOURNAL surgeries requiring personal protective equipment (PPE), postoperative intensive care, or recovery bed should be delayed. Moreover, the follow-up visit after a previously-performed surgery is better to be provided virtually or by a tele-visit (over the phone or computer), as much as possible (9).

However, how to categorize the surgery type? Is it an emergency or not? And how to judge the risk stratification for the patients? The primary example of this false dichotomy is cancer surgery, which does not fall into one particular category (10). Several surgical societies (11) have made recommendations as regards deferring some cancer surgeries. But, the surgical delay has its consequences, specifically for patients who initiated neoadjuvant chemotherapy and preparing for surgery (10).
Besnier E. et al. proposed an algorithm for scheduling of surgical procedures in the Covid-19 pandemic period, which concluded that SARS-Cov-2 infection, as well as significant surgeries, induce a severe inflammatory stress response and derangement of immunity, suggesting an elevated risk of postoperative complications and mortality in these patients. Therefore, risk stratification based on a case-by-case decision in association with the need for public health priority in the form of reservation of intensive care units and working health personnel $(\underline{12})$. Recently, an article from France sumarized a strategy for dealing with patients requiring digestive and oncological surgeries (Table 1).

\begin{tabular}{|c|c|}
\hline \multicolumn{2}{|r|}{ General Principles } \\
\hline $\begin{array}{l}\text { For pre-cancerous } \\
\text { lesions with good } \\
\text { prognosis (T1-2, } \\
\text { N0) }\end{array}$ & it is advised to defer surgery according to the stage of the epidemic. \\
\hline $\begin{array}{l}\text { For cancers } \mathrm{T} 3-4 \\
\text { and/or } \mathrm{N}+\end{array}$ & $\begin{array}{l}\text { Chemoradiotherapy is indicated. Short radiotherapy is to be discussed (followed } \\
\text { by a waiting period) to reduce the exposure time in the hospital and avoid } \\
\text { infections. Induction chemotherapy can also be discussed case by case. }\end{array}$ \\
\hline $\begin{array}{l}\text { For cancers at the } \\
\text { end of treatment } \\
\text { where surgery must } \\
\text { be scheduled, }\end{array}$ & $\begin{array}{l}\text { the strategy will be adapted to the duration of the epidemic, its peak, and the } \\
\text { available medical resources. In some cases, interim chemotherapy can be proposed }\end{array}$ \\
\hline \multicolumn{2}{|r|}{ For colonic tumours } \\
\hline $\begin{array}{l}\text { For advanced } \\
\text { colonic lesions }\end{array}$ & $\begin{array}{l}\text { neoadjuvant chemotherapy and wait until the peak of the epidemic has passed } \\
\text { before proposing radical surgery but should be on a case-by-case basis. }\end{array}$ \\
\hline $\begin{array}{l}\text { For cancers with } \\
\text { obstruction }\end{array}$ & a stoma will be performed followed by chemotherapy \\
\hline \multicolumn{2}{|r|}{ For Pancreatic tumours } \\
\hline \multicolumn{2}{|c|}{ - If there is no histological documentation: } \\
\hline $\begin{array}{l}\text { For peri- } \\
\text { ampullary } \\
\text { tumours }\end{array}$ & $\begin{array}{l}\text { deferral of surgery will be proposed according to the operative risks as the } \\
\text { epidemic unfolds }\end{array}$ \\
\hline $\begin{array}{ll}\text { For } \\
\text { corporoca } \\
\text { udal } \\
\text { lesions } \\
\end{array}$ & $\begin{array}{l}\text { according to possibilities of access to surgery and how the epidemic is evolving, } \\
\text { surgery can be proposed to patients at low operative risk but must otherwise be } \\
\text { deferred. }\end{array}$ \\
\hline If there is hist & ma: \\
\hline
\end{tabular}


- Interim chemotherapy can be proposed for cephalic lesions. These situations will be discussed case by case to take into consideration the oncological risk and the risk of induced immunodepression, which could be extremely harmful (biliary drainage and malnutrition in particular).

- For lesions requiring left splenopancreatectomy, surgery can be proposed in patients at low operative risk (comorbidities, nutritional state), but must otherwise be deferred, with possible interim chemotherapy. These situations will be discussed case by case to take into consideration the oncological risk and the risk of induced immunodepression, which could be extremely harmful.

\section{For Liver Tumours}

\begin{tabular}{|l|l|}
$\begin{array}{l}\text { For patients with } \\
\text { early liver tumours, }\end{array}$ & $\begin{array}{l}\text { Given the low risk of tumours growth throughout the epidemic, surgery must be } \\
\text { deferred }\end{array}$ \\
\hline $\begin{array}{l}\text { For a lesion } \\
\text { amenable to minor } \\
\text { hepatic resection, }\end{array}$ & $\begin{array}{l}\text { According to the possibilities of access to surgery and how the epidemic unfolds, } \\
\text { surgery can be proposed to patients at low operative risk but must otherwise be } \\
\text { deferred. }\end{array}$ \\
\hline $\begin{array}{l}\text { For a lesion } \\
\text { requiring major } \\
\text { hepatic resection }\end{array}$ & $\begin{array}{l}\text { Surgery must be deferred, with possible preparation by portal embolization, if } \\
\text { necessary, and nutritional preparation. Special attention will be paid to hilar } \\
\text { cholangiocarcinoma, as regards septic and nutritional risk. }\end{array}$ \\
\hline $\begin{array}{l}\text { For patients who } \\
\text { are candidates for } \\
\text { tumours } \\
\text { destruction by } \\
\text { thermal ablation, }\end{array}$ & $\begin{array}{l}\text { They can be treated according to the possibilities of access to surgery and } \\
\text { interventional radiology facilities and how the epidemic unfolds. }\end{array}$ \\
\hline
\end{tabular}

It is advised to postpone any elective operations for benign lesions. They recommended that diseases that could not be delayed for a period more than one month should be operated by minimally invasive procedures if possible. This aims to decrease the burden on the respiratory system. The laparoscopy and endoscopy, which are aerosol-generating tools, have many advantages of being minimally invasive procedures with a little impact on the respiratory function. However, care should be taken from the exsufflated gases with the aerosol release, which could contaminate the health care workers, the furniture, and room surfaces via airborne particles (13).

Similarly, other studies ( $\underline{6}, \underline{7})$ recommended to cancel all the elective operations and emphasized that surgeons should only perform the emergency and all carcinologic surgery. Zheng $\mathrm{MH}$ et al. (7), advised using the laparoscopic procedures in these types of surgeries, but with extreme precautions, which include:

- Surgeons or endoscopists should wear full PPE, including N95 masks or other air-purifying respirators. Adequate air-exchange periods with minimal staff in the OR should be considered if laparoscopic surgery is scheduled.

- Special attention to the establishment of pneumoperitoneum, hemostasis, and cleaning at trocar sites to prevent any gush of body fluid. As recently discovered, the SARS-CoV-2 is present in the peritoneal fluids (14)

- Use the lowest intraoperative pneumoperitoneum pressure and $\mathrm{CO} 2$ ventilation with reducing the Trendelenburg position time as much as possible. This decreases the burden 
on the respiratory and circulatory systems.

- Using electrocautery as low power as possible and shorten the dissecting times to reduce the surgical smoke.

Furthermore, a Chinese article (15) proposed three significant strategies for patients with malignancy in this pandemic and other attacks of severe contagious diseases in the future. First, the deferring of adjuvant chemotherapy or elective surgery for stable cancer should be considered. Second, maximum personal protection and precautions should be taken for patients with cancer or cancer survivors. Third, more intensive screening or treatment should be considered when patients with cancer are infected with SARS-CoV-2, especially in geriatric age or those with other comorbidities (15).

For anesthetic precautions, a study from Singapore (ㅁ) suggested an intubationextubation protocol during the pandemic that could greatly decrease the viral infection rate while performing these surgeries. These measures included:

- Intubation to be performed by one anesthetist, surgeon, and nurse in the OR.

- All persons in the OR during the intubation process should wear an N95 mask and eye protection.

- Anesthetist to announce 'Clear OR, intubation now' to vacate personnel out of OR during intubation.

- For all non-laparoscopic surgeries: the surgical team must wait $5 \mathrm{~min}$ after intubation to allow clean scrub of air. (Note: the OR performs 25 cycles of air exchange per hr, $100 \%$ fresh air will be circulated in OR within $2.5 \mathrm{~min}$; the $5 \mathrm{~min}$ allowance will ensure two cycles of air exchange are performed). The operation to proceed with surgical masks.
- Extubation to be done only with the anesthetist team in OR. Anesthetist to announce 'Clear OR, extubation now' to initiate extubation. The rest of the surgical team to vacate the $R$.

- Anesthetist to announce 'Extubation complete' after the patient is fully extubated. The rest of the surgical team members to wait $5 \mathrm{~min}$ after extubation before returning to OR.

- For all laparoscopic surgeries: staff to be in N95 masks throughout the case and can remain in OR during intubation and extubation.

- Doors are locked at the induction of anesthesia and will remain so until 15 min after deflation of pneumoperitoneum. Access to the induction room is permitted.

- Upon final deflation of pneumoperitoneum, circulating nurse to start timer countdown for $15 \mathrm{~min}$. Doors remain closed until $15 \mathrm{~min}$ is up.

- At extubation, staff in N95 can remain. OR doors to remain closed until 5 min after the end of extubation.

Moreover, the patient should wear a surgical mask during the procedure, if possible, with avoidance of administration of high-flow supplemental oxygen. If necessary, supplemental oxygen should be provided through a nasal cannula using low flows (16).

\section{Conclusion:}

Elective surgeries are recommended to be discontinued to avoid patients and health professional's morbidity. Emergency and oncological surgeries to be performed with extreme precautions.

\section{REFERENCES}

1. Ciotti M, Angeletti S, Minieri M, Giovannetti M, Benvenuto D, Pascarella 
S, et al. COVID-19 Outbreak: An Overview. Chemotherapy. 2020:1-9.

2. Lai CC, Shih TP, Ko WC, Tang HJ, Hsueh PR. Severe acute respiratory syndrome coronavirus 2 (SARS-CoV-2) and coronavirus disease-2019 (COVID19): The epidemic and the challenges. Int J Antimicrob Agents. 2020;55(3):105924.

3. Wang $\mathrm{D}, \mathrm{Hu} \mathrm{B}, \mathrm{Hu} \mathrm{C}$, Zhu F, Liu X, Zhang J, et al. Clinical Characteristics of 138 Hospitalized Patients With 2019 Novel Coronavirus-Infected Pneumonia in Wuhan, China. JAMA. 2020.

4. Wang XW, Li J, Guo T, Zhen B, Kong $\mathrm{Q}$, Yi B, et al. Concentration and detection of SARS coronavirus in sewage from Xiao Tang Shan Hospital and the 309th Hospital of the Chinese People's Liberation Army. Water Sci Technol. 2005;52(8):213-21.

5. van Doremalen N, Bushmaker T, Morris DH, Holbrook MG, Gamble A, Williamson BN, et al. Aerosol and Surface Stability of SARS-CoV-2 as Compared with SARS-CoV-1. N Engl J Med. 2020.

6. Chew $\mathrm{MH}, \mathrm{Koh} \mathrm{FH}, \mathrm{Ng} \mathrm{KH}$. A call to arms: a perspective of safe general surgery in Singapore during the COVID19 pandemic. Singapore Med J. 2020.

7. Zheng $\mathrm{MH}$, Boni L, Fingerhut $\mathrm{A}$. Minimally Invasive Surgery and the Novel Coronavirus Outbreak: Lessons Learned in China and Italy. Ann Surg. 2020.

8. Ball CG. COVID-19: a time of crisis, but also of surgical opportunity and optimism. Can J Surg. 2020;63(2):e164.

9. Surgeons ACo. Guidelines for Triage of Non-Emergent Surgical Procedures March 31, 2020 [Available from: https://www.facs.org/-

/media/files/covid19/information-forsurgeons/triage.

10. Oliver S. Eng M, Jennifer Tseng M, Aslam Ejaz M, MPH2; , Timothy M. Pawlik M, PhD, MPH2; , Peter Angelos M, PhD1. Apples to Oranges: Ethical Considerations in COVID-19 Surgical Recovery. Annals of Surgery. 2020.

11. Bartlett DL, Howe JR, Chang G, Crago A, Hogg M, Karakousis G, et al. Management of Cancer Surgery Cases During the COVID-19 Pandemic: Considerations. Ann Surg Oncol. 2020.

12.Besnier E, Tuech JJ, Schwarz L. We Asked the Experts: Covid-19 Outbreak: Is There Still a Place for Scheduled Surgery? "Reflection from Pathophysiological Data". World J Surg. 2020;44(6):1695-8.

13. Tuech JJ, Gangloff A, Di Fiore F, Michel P, Brigand C, Slim K, et al. Strategy for the practice of digestive and oncological surgery during the Covid-19 epidemic. J Visc Surg. 2020.

14.Federico Coccolini MD (1), Dario Tartaglia MD (1), Adolfo Puglisi MD (1), Cesira Giordano PhD (2), Mauro Pistello PhD (2), Marianna Lodato MD (3), et al. SARS-CoV-2 is present in peritoneal fluid in COVID-19 patients. Annals of Surgery. 2020.

15.Wenhua Liang, Weijie Guan, Ruchong Chen, Wei Wang, Jianfu Li, Ke Xu, et al. Cancer patients in SARS-CoV-2 infection: a nationwide analysis in China. The Lancet Oncology. February 14, 2020; Vol 21.

16. Rajan N, Joshi GP. The COVID-19: Role of Ambulatory Surgery Facilities in This Global Pandemic. Anesth Analg. 2020. 